\title{
The case of $\mathrm{HCOOH}$ on (101) anatase $\mathrm{TiO}_{2}$ : where is the acid proton?
}

\author{
Gloria Tabacchi, ${ }^{[\mathrm{a}]}$ Marco Fabbiani, ${ }^{[\mathrm{b}]}$ Lorenzo Mino, ${ }^{[\mathrm{b}]}$ Gianmario Martra, ${ }^{[\mathrm{b}]}$ and Ettore Fois ${ }^{\star[a]}$
}

\begin{abstract}
Carboxylic acids adsorption on anatase $\mathrm{TiO}_{2}$ is a relevant process in many technological applications. Yet, in spite of several decades of investigations, the acid proton localization - either on the molecule or on the surface - is still an open issue. By modeling the adsorption of formic acid on top of (101) anatase surfaces, we highlight the formation of a short-strong hydrogen bond. In the $0 \mathrm{~K}$ limit, the acid proton behavior is ruled by quantum delocalization effects in a single potential well, while at room conditions the proton undergoes a rapid classical shuttling in a shallow two-wells free energy profile. This picture, supported by agreement with available experiments, shows that the anatase surface acts like a protecting group for the carboxylic acid functionality. Such a new conceptual insight might help rationalize chemical processes involving carboxylic acids on oxide surfaces.
\end{abstract}

Atomistic insight of adsorbed - $\mathrm{COOH}$ groups on titanium dioxide is of key relevance in photocatalysis and environmental remediation processes. ${ }^{[1,2]}$ For example, the interaction of carboxylic groups with $\mathrm{TiO}_{2}$ surfaces governs the anchoring of solar cell sensitizers. ${ }^{[3]}$ Also, $\mathrm{TiO}_{2}$ catalyzes, in the absence of any solvent, the direct amidation of $\mathrm{R}-\mathrm{COOH}$ with amines ${ }^{[4]}$ and amino acid oligomerization in prebiotic conditions. ${ }^{[5-7]}$ Noteworthy, atmospheric carboxylic acids form a self-assembled monolayer on rutile $\mathrm{TiO}_{2}$ (110), showing an impressive adsorption selectivity with respect to alcohols, present in much higher concentrations. ${ }^{[8]}$ This behavior, proposed to have a huge impact on both self-cleaning properties and photocatalytic performances of $\mathrm{TiO}_{2}$, was rationalized by the atomistic details of the formate adsorption geometry. Indeed, the dissociative adsorption of $\mathrm{HCOOH}$ on rutile $\mathrm{TiO}_{2}(110)$ in a bidentate mode is now firmly established at both low and high coverages. ${ }^{[8-10]}$ On the contrary, for anatase, which is the preferred $\mathrm{TiO}_{2}$ form in many technological applications, the adsorption of small carboxylic acids still shows puzzling aspects. ${ }^{[1-18]}$ This holds especially true for the most stable surface of this titania form, the (101) one, which is also the principal termination of anatase nanoparticles. ${ }^{[11,13,14,19-21]}$ One of the main issues stems from the results of IRRAS and STM surface science experiments dealing with the adsorption of $\mathrm{HCOOH}^{[22]}$ and $\mathrm{H}_{3} \mathrm{C}-\mathrm{COOH},{ }^{[23]}$ respectively, on non-defective terminations of anatase (101)

[a] G. Tabacchi, E. Fois

Department of Science and High Technology

University of Insubria and INSTM

via Valleggio 9, I-22100 Como, Italy

E-mail: ettore.fois@uninsubria.it

[b] M. Fabbiani, L. Mino, G.Martra

Department of Chemistry and Nanostructured Interfaces and

Surfaces NIS interdepartmental centre

University of Torino

via P. Giuria 7, I-10125 Torino, Italy

Supporting information for this article is given via a link at the end of the document single crystals. In both cases, the features of the signals related to the $\mathrm{HCOO} / \mathrm{H}_{3} \mathrm{C}-\mathrm{COO}$ moieties pointed toward the occurrence of a dissociative adsorption. Conversely, neither IRRAS nor STM studies gave clear indications of the acid proton fate: no $\mathrm{OH}$ stretching signal was detected by IRRAS, and no surface hydroxyl groups were found in STM analyses. Thus, a simple, but fundamental question arises: where is the missing proton? Here we report a new finding shedding light on this problem: the acid proton is shared between the carboxylate group and a surface oxygen, and forms a short-strong-hydrogen-bond (SSHB). The proton behavior is ruled by quantum delocalization at low temperature and by thermally activated shuttling at room temperature. This picture, obtained from modeling yet in line with experiments, suggests that the catalytic oxide surface acts as a protecting group with respect to Brønsted acid functionality. To trace the fate of the formic acid proton, we first perform DFTbased $^{[24]}$ first principles molecular dynamics (FPMD) ${ }^{[25,26]}$ at room-temperature conditions, because thermal effects crucially influence the behavior at molecule-material interfaces. ${ }^{[19,27-32]}$ We focus on a regular non-defective (101) model, and adopt different anchoring geometries for $\mathrm{HCOOH}$.

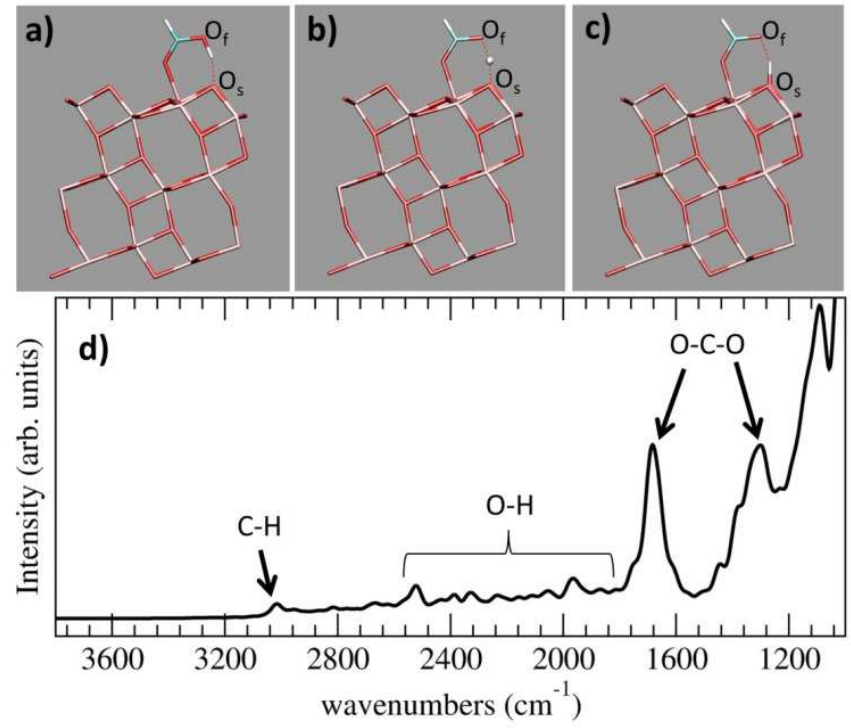

Figure 1. a-c: Snapshots from a $300 \mathrm{~K}$ simulation of monodentate $\mathrm{HCOOH}$ on $\mathrm{TiO}_{2}(101)$; a) undissociated $\mathrm{HCOOH}$ strongly hydrogen bonded to a surface oxygen $\mathrm{O}_{s}$; b) the acid proton is shuttling between the formate moiety and the surface; c) $\mathrm{O}_{\mathrm{s}}$ is now protonated, and strongly hydrogen bonded to the formate. d) IR spectrum calculated from this trajectory. Wavenumbers were scaled using a scaling factor of 1.0678 (see SI).

The starting point was a structure proposed on the basis of IRRAS spectra, ${ }^{[22]}$ depicting the dissociation of $\mathrm{HCOOH}$ in a $\mathrm{HCOO}^{-}$monodentate to a surface $\mathrm{Ti}\left(\mathrm{Ti}_{\mathrm{s}}\right)$ and a proton transferred to an oxygen atom of the surface $\left(\mathrm{O}_{s}\right)$, no longer 
interacting with the formate. This system resulted thermally unstable: after few ps of FPMD at $300 \mathrm{~K}$, the $\mathrm{HCOO}^{-}(\mathrm{Ti})$ and $\mathrm{H}^{+}\left(\mathrm{O}_{\mathrm{s}}\right)$ adducts relaxed to a undissociated $\mathrm{HCOOH}$ monodentate to a $\mathrm{Ti}_{\mathrm{s}}$ (see $\mathrm{SI}$ for details). Moreover, the $\mathrm{H}^{+}\left(\mathrm{O}_{\mathrm{s}}\right)$ stretching mode shows a well defined frequency $\left(3621.3 \mathrm{~cm}^{-1}\right)$, whereas no signal attributable to the $\mathrm{OH}$ stretching mode was detected in IRRAS measurements. ${ }^{[22]}$ The attention was then turned to the $300 \mathrm{~K}$ trajectories where $\mathrm{HCOOH}$ maintains monodentate adsorption with one oxygen bonded to a 5-coordinated $\mathrm{Ti}$ (Figure 1a-c). Nonetheless, the other carboxyl oxygen $O_{f}$ initially protonated, forming an $\mathrm{OH}$ moiety hydrogen bonded to a surface oxygen $\mathrm{O}_{\mathrm{s}}$ - is, on average, only transiently protonated at $300 \mathrm{~K}$, as the acid proton shuttles between $\mathrm{O}_{\mathrm{f}}$ (Figure 1a) and $\mathrm{O}_{\mathrm{s}}$ (Figure 1c) (see SI, movie M1). The spectroscopic signature of this regime is a very broad and low-intensity band in the 2500$1800 \mathrm{~cm}^{-1}$ region (Figure 1d; see SI, Figure S4 for other simulated IR patterns), likely difficult to be observed in experimental spectra. On the other hand, the calculated O-C-O vibrational features of the monodentate adduct (1680 and 1290 $\mathrm{cm}^{-1}$ ) are in good agreement with IRRAS data (1647 and 1315 $\mathrm{cm}^{-1}$ ). So low $\mathrm{OH}$ stretching frequencies are peculiar of strong hydrogen bonds $X \cdot \cdot H \cdot \cdot Y$ in molecular systems with short $X-Y$ distances, ${ }^{[33]}$ and are also found in proton sharing moieties in condensed phases. ${ }^{[34-38]}$ As a matter of fact, in our simulation the average $\mathrm{O}_{\mathrm{f}}-\mathrm{O}_{\mathrm{s}}$ distance is $2.484 \AA$, typical of SSHB .
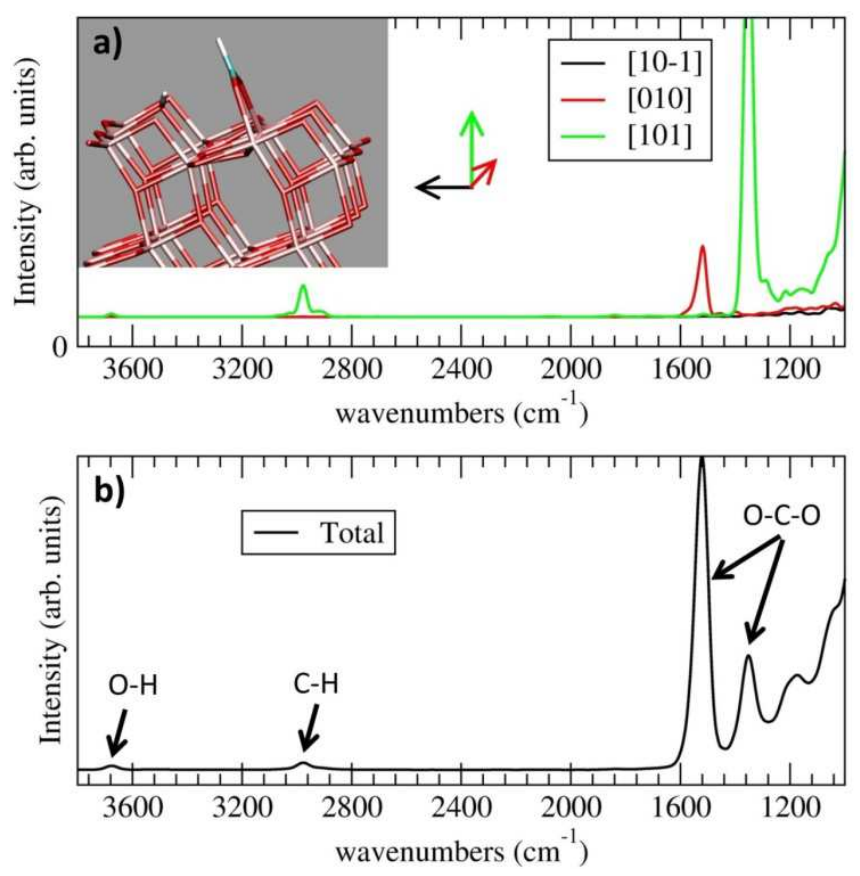

Figure 2. a) Inset: Snapshot from a $300 \mathrm{~K}$ simulation of (dissociated) bridging formate on $\mathrm{TiO}_{2}(101)$. Vibrational spectra: Fourier-transforms of the autocorrelation function for the three dipole moment components calculated from this simulation. b) IR spectrum calculated by Fourier-transform of the total dipole moment autocorrelation function. Wavenumbers were scaled using a scaling factor of 1.0678 (see SI). formate ( $\mathrm{HCOO}^{-}$) moiety located on top of a protonated regular (101) facet in a bidentate bridging mode. Calculated IR signals and significant snapshots from FPMD are shown in Figure 2 (see also SI, Figure S4, for other simulated IR patterns). By inspecting the components of the IR pattern (Figure 2a), we notice a strong signal of the [010] component, which should correspond to a strong negative IRRAS band (see ref. ${ }^{[22]}$ for details). Indeed, such band - as well as the signal due to $v(\mathrm{OH})$, here calculated at $3680 \mathrm{~cm}^{-1}$ (Figure 2b), were missing in the experimental spectra. Moreover, in this case the calculated O-C$O$ vibrational features (1520 and $1360 \mathrm{~cm}^{-1}$, Figure $2 \mathrm{~b}$ ) were in a definitely worse agreement with respect to those in IRRAS spectra (see above). All relevant vibrational frequencies are listed in Table 1, also compared with the harmonic frequencies calculated for the minima commented on below.

Table 1. Positions of IR signals $\left(\mathrm{cm}^{-1}\right)$ calculated for surface adducts in Figures 1-2, and harmonic frequencies for the minima in Figure 3.

\begin{tabular}{llll}
\hline & $v(\mathrm{C}-\mathrm{H})$ & $v(\mathrm{O}-\mathrm{H})$ & $v(\mathrm{O}-\mathrm{C}-\mathrm{O})$ \\
\hline Experimental $^{[\mathrm{a}]}$ & $\begin{array}{l}\text { Not } \\
\text { reported }\end{array}$ & $\begin{array}{l}\text { Not } \\
\text { detected }\end{array}$ & $1647 ; 1315$ \\
\hline First-Principles MD & & & \\
\hline Monodentate & $2900-3000$ & $1800-2500$ & $1680 ; 1290$ \\
$\begin{array}{l}\text { Bridging HCOO }\left(\mathrm{Ti}_{\mathrm{s}}\right) \\
\mathrm{H}^{+}\left(\mathrm{O}_{\mathrm{s}}\right)\end{array}$ & $2900-3000$ & 3680 & $1520 ; 1360$ \\
\hline Harmonic Frequencies & & & $1653 ; 1442$ \\
\hline $\begin{array}{l}\text { undissociated (II) } \\
\text { shared-H (III) }\end{array}$ & 3014 & 2370 & $1530 ; 1359$ \\
dissociated (I) & 2983 & 1676 & $1570 ; 1346$ \\
\hline
\end{tabular}

[a] Experimental data ${ }^{[22]}$ included for comparison refer to monodentate species on non-defective (101) anatase.

As the molecule-surface proton-shuttling could be relevant for $\mathrm{HCOOH}$ reactivity on anatase, we calculated the free energy path $^{[39]}$ for this process at $50 \mathrm{~K}$ and $300 \mathrm{~K}$ (Figure 3a, including also data at $0 \mathrm{~K}$, see below).

In both cases we found two free energy minima, corresponding to the dissociated (I) and non-dissociated (II) forms. The barrier is clearly small $(0.84$ and $1.17 \mathrm{kcal} / \mathrm{mol}$ at 50 and $300 \mathrm{~K}$, respectively): in term of $\mathrm{kT}$ (Figure $3 \mathrm{~b}$ ) the barrier $(8.5 \mathrm{kT}$ at $50 \mathrm{~K})$ decreases to only $2.0 \mathrm{kT}$ at $300 \mathrm{~K}$, indicating that proton shuttling can be operative at room conditions. Also, temperature copes to reduce the thermodynamic stability difference between the two forms (which is $6.4 \mathrm{kT}$ at $50 \mathrm{~K}$ and $0.9 \mathrm{kT}$ at $300 \mathrm{~K})$.

For the sake of completeness, we considered the case of a stable dissociative adsorption of $\mathrm{HCOOH}$, resulting from a 

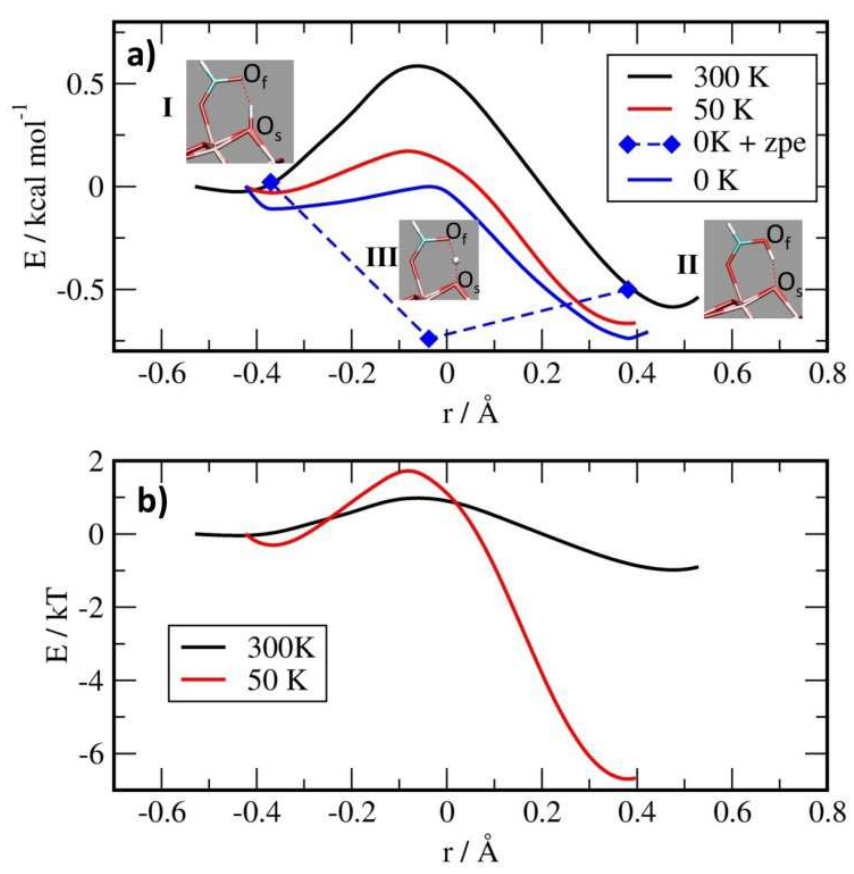

Figure 1. a) Free energy profiles for proton shuttling at $300 \mathrm{~K}$ and $50 \mathrm{~K}$. The reaction coordinate $\mathrm{r}=\mathrm{r}\left(\mathrm{H}-\mathrm{O}_{\mathrm{s}}\right)-\mathrm{r}\left(\mathrm{H}-\mathrm{O}_{\mathrm{f}}\right)$ is defined as the difference between the distances of the proton from carboxylate oxygen $\mathrm{O}_{f}$ and surface oxygen $\mathrm{O}_{s}$, respectively (estimated error bar: $0.1 \mathrm{kcal} / \mathrm{mol}$ ). Blue diamonds: zpe-corrected relative energies of the $0 \mathrm{~K}$ optimized geometry of the dissociated (I), undissociated (II) and proton-sharing (III) forms of the adsorbate. b) Free energy profiles at $300 \mathrm{~K}$ and $50 \mathrm{~K}$ in $\mathrm{kT}$-units.

Starting from the $50 \mathrm{~K}$ free energy profile, we calculated energy minima (at $0 \mathrm{~K}$ ) at different levels of theory. At the $P B E^{[24]}$ level we found modest energy differences, with a preference for structure II by $0.67 \mathrm{kcal} / \mathrm{mol}$ and a $(0 \mathrm{~K})$ barrier of $0.75 \mathrm{kcal} / \mathrm{mol}$. By including dispersion corrections, ${ }^{[40]}$ form II is more stable by $0.48 \mathrm{kcal} / \mathrm{mol}$ and the shuttling barrier is $0.68 \mathrm{kcal} / \mathrm{mol}$. Such a trend is not quantitatively confirmed by the $\mathrm{PBE} 0^{[41]}$ data, which predict form I more stable by $0.88 \mathrm{kcal} / \mathrm{mol}$ and a shuttling barrier of $0.95 \mathrm{kcal} / \mathrm{mol}$. However, the PBE0 results confirm that the energy difference between the two structures is limited, therefore we can conclude that the $0 \mathrm{~K}$ energy differences involving monodentate $\mathrm{HCOOH}$ are all within $1 \mathrm{kcal} / \mathrm{mol}$, irrespective of the adopted level of theory.

For the two PBE minima we calculated the harmonic frequencies (Table 1): in line with the spectrum from the $300 \mathrm{~K}$ simulation (Figure 2d), there are no $\mathrm{OH}$ signals at wavenumbers $>3000 \mathrm{~cm}^{-1}$, and the $\mathrm{CH}$ stretching modes are found at much higher energy than the acid proton modes. Such low values for $v(\mathrm{OH})$ are due to very strong molecule-surface hydrogen bonding, as indicated by the $\mathrm{O}_{s}-\mathrm{O}_{f}$ separation found in the minimum structures I and II - $2.463 \AA$ and $2.479 \AA$, respectively.

So far we discussed the thermal behavior of $\mathrm{HCOOH}$ on $\mathrm{TiO}_{2}$ anatase in a purely classical mechanics frame. Actually, formic acid protons ${ }^{[35,42-45]_{-}}$and in general proton transfer events $^{[46-50]}$ - can be strongly influenced by quantum effects, in particular by zero point energies (zpe). ${ }^{[46]}$ To gather insight, we optimized the structure of the activated complex III at the PBE level (see SI for details). The harmonic frequency involving the shared proton resulted $1676 \mathrm{~cm}^{-1}$ (with an $\mathrm{O}_{\mathrm{s}}-\mathrm{O}_{\mathrm{f}}$ distance of $2.395 \AA$ ), not surprisingly even lower than the wavenumbers found for the double-well species I and II. By adding to the energy of the three optimized configurations the zpe, the barrier disappears (see Figure 3a): hence, the quantum approach predicts a shared proton in a single well at $0 \mathrm{~K}$. Yet the energy differences still remain below $1 \mathrm{kcal} / \mathrm{mol}$, even upon inclusion of the zpe contribution. This result indicates that, to ascertain whether the molecule-surface proton motion is governed by a single-well or a double-well potential, one should rest on electronic-structure calculations assuring at least $0.1 \mathrm{kcal} / \mathrm{mol}$ accuracy, which are hardly feasible for systems of this size. ${ }^{[51]}$

Our study opens an intriguing question - single vs doublewell potential for acid protons at bare $\mathrm{TiO}_{2}$ interfaces, while providing useful chemical insight on the surface behavior of carboxylic functionalities. Firstly, both the IR signal due to classic proton shuttling (Figure 2d), and the harmonic frequency associated to the quantum mechanical minimum $\left(1676 \mathrm{~cm}^{-1}\right)$ fall in the region of strong hydrogen bonds - i.e., below the $\mathrm{CH}$ stretching modes and very close to the highest O-C-O mode of adsorbed $\mathrm{HCOOH}$. Such information may help experimentalists in identifying shared or shuttling protons from the presence of low-wavenumber (and presumably very broad and with a low intensity at maximum) $v(\mathrm{OH})$ signals in vibrational spectra of adsorbed carboxylic acids. Our floating proton model might also explain the reported STM acid proton "invisibility", ${ }^{[23]}$ as the carboxylate group could conceal the proton from the tip.

Secondly, earlier studies on nuclear quantum effects in molecular systems showed that, while quantum fluctuations and zero point motion dominate at very low temperature, the thermally activated ("classical") behavior should prevail at room temperature. ${ }^{[46,52,53]}$ To explore this hypothesis, we simulate, at room conditions, the adsorption of a species less sensitive than $\mathrm{HCOOH}$ to quantum delocalization effects: ${ }^{[46,54]}$ deuterated formic acid (DCOOD). This $300 \mathrm{~K}$ simulation reveals that even the acid deuteron shuttles between $\mathrm{TiO}_{2}$ surface oxygen and a carboxylic oxygen (See Figure S5). Hence, a "classic" doublewell model may be eligible to describe $\mathrm{HCOOH}$ adsorption on defect-free portions of anatase $\mathrm{TiO}_{2}\{101\}$ at room temperature.

A third remark, which is more chemical in nature, is that both the quantum and the classical pictures predict that $\mathrm{HCOOH}$ on $\mathrm{TiO}_{2}$ anatase is essentially a neutral moiety (see SI, Table S2). Hence, its reactivity may be different from that of a fullydissociated formic acid - i.e. a negatively charged formate and a surface hydroxyl group. Our floating proton is encaged between one carboxyl oxygen and a surface oxygen, and it is strongly coupled, both electronically and vibrationally, to the $\mathrm{TiO}_{2}$ lattice (see SI, Figures S6-S8). As a consequence, a SSHB with covalent character is formed, which damps the Brønsted acid functionality of formic acid. This protecting-group role of the surface could explain, for example, why carboxylic acids preadsorbed on $\mathrm{TiO}_{2}$ nanoparticles undergo amidation instead of salt formation upon addition of amines. ${ }^{[4]}$

In conclusion, we propose a dynamic model of the adsorption of small carboxylic acids on anatase- $\mathrm{TiO}_{2}$, which is consistent with experiments, and involves either a rapid proton shuttling between a carboxylic and a surface oxygen, or a proton sharing 
due to quantum delocalization. Whereas the quantum mechanical picture should dominate at low temperatures, molecule-to-surface proton shuttling (classical mechanical picture) should be the prevailing mechanism at room conditions. In both cases, the acid proton is coupled both to the molecule and to $\mathrm{TiO}_{2}$ via a SSHB. Short HBs with low barriers are considered essential in enhancing catalytic rates of enzymatic reactions (see e.g. Refs. ${ }^{[55-57]}$ ). Strong HBs have been also observed at the surface of some inorganic materials and polymers upon interaction of surface (super)acid protons with adsorbed base molecules. ${ }^{[58]}$ The peculiarity of our case is that the strong $\mathrm{HB}$ arises upon adsorption of a weak acid on a weakly reactive surface, and protects the acid functionality of the carboxylic group. Hence, two ideas quintessential of organic synthesis (protecting-group) and enzymatic catalysis (SSHB), meld together in a new surface chemistry concept, that may help interpreting behavior, reactivity and catalytic processes involving acid protons and carboxyl groups at material interfaces.

\section{Acknowledgements}

FAR2017 Uninsubria is acknowledged for funding.

Keywords: density functional calculations $\cdot$ molecular dynamics -surface chemistry $\cdot$ vibrational spectroscopy $\cdot$ zero point energy

[1] Y. Ma, X. Wang, Y. Jia, X. Chen, H. Han, C. Li, Chem. Rev. 2014, 114, 9987-10043.

[2] A. Fujishima, X. Zhang, D. A. Tryk, Surf. Sci. Rep. 2008, 63, 515-582.

[3] F. Schiffmann, J. VandeVondele, J. Hutter, R. Wirz, A. Urakawa, A. Baiker, J. Phys. Chem. C 2010, 114, 8398-8404.

[4] C. Deiana, Y. Sakhno, M. Fabbiani, M. Pazzi, M. Vincenti, G. Martra, Chem CatChem 2013, 5, 2832-2834.

[5] G. Martra, C. Deiana, Y. Sakhno, I. Barberis, M. Fabbiani, M. Pazzi, M. Vincenti, Angew. Chem. Int. Ed. 2014, 53, 46714674; Angew. Chem. 2014, 126, 4759-4762.

[6] M. Fabbiani, M. Pazzi, M. Vincenti, G. Tabacchi, E. Fois, G. Martra, J. Nanosci. Nanotechnol. 2018, 18, 5854-5857.

[7] J.-F. Lambert, Orig. Life Evol. Biosph. 2008, 38, 211-242.

[8] J. Balajka, M. A. Hines, W. J. I. DeBenedetti, M. Komora, J. Pavelec, M. Schmid, U. Diebold, Science 2018, 361, 786-789.

[9] A. Mattsson, S. Hu, K. Hermansson, L. Österlund, J. Chem. Phys. 2014, 140, 034705.

[10] M. J. Tillotson, P. M. Brett, R. A. Bennett, R. Grau-Crespo, Surf. Sci. 2015, 632, 142-153.

[11] X. Gong, A. Selloni, A. Vittadini, J. Phys. Chem. B 2006, 110, 2804-2811.

[12] X. Q. Gong, A. Selloni, J. Catal. 2007, 249, 134-139.

[13] A. Tilocca, A. Selloni, J. Phys. Chem. B 2004, 108, 4743-4751.

[14] A. Vittadini, A. Selloni, F. P. Rotzinger, M. Grätzel, J. Phys. Chem. B 2000, 104, 1300-1306.

[15] F. Nunzi, F. De Angelis, J. Phys. Chem. C 2011, 115, 21792186.

[16] L. Kou, T. Frauenheim, A. L. Rosa, E. N. Lima, J. Phys. Chem. C 2017, 121, 17417-17420.

[17] K. L. Miller, J. L. Falconer, J. W. Medlin, J. Catal. 2011, 278, 321-328.

[18] Y. Li, Y. Gao, Langmuir 2018, 34, 546-552.

[19] C. Deiana, M. Minella, G. Tabacchi, V. Maurino, E. Fois, G. Martra, Phys. Chem. Chem. Phys. 2013, 15, 307-15.

[20] C. Deiana, G. Tabacchi, V. Maurino, S. Coluccia, G. Martra, E. Fois, Phys. Chem. Chem. Phys. 2013, 15, 13391-13399.

[21] C. Deiana, E. Fois, G. Martra, S. Narbey, F. Pellegrino, G. Tabacchi, ChemPhysChem 2016, 17, 1956-1960.

[22] M. Xu, H. Noei, M. Buchholz, M. Muhler, C. Wöll, Y. Wang,
Catal. Today 2012, 182, 12-15.

[23] D. C. Grinter, M. Nicotra, G. Thornton, J. Phys. Chem. C 2012, 116, 11643-11651.

[24] J. P. Perdew, K. Burke, M. Ernzerhof, Phys. Rev. Lett. 1996, 77, 3865-3868.

[25] CPMD code, IBM Corp. 1990-2019, MPI für

Festkörperforschung Stuttgart 1997-2001, 2019.

[26] R. Car, M. Parrinello, Phys. Rev. Lett. 1985, 55, 2471-2474.

[27] S. Hu, P. A. Bopp, L. Österlund, P. Broqvist, K. Hermansson, J. Phys. Chem. C 2014, 118, 14876-14887.

[28] C. Spreafico, F. Schiffmann, J. VandeVondele, J. Phys. Chem. C 2014, 118, 6251-6260.

[29] L. Martínez-Suarez, N. Siemer, J. Frenzel, D. Marx, ACS Catal. 2015, 5, 4201-4218.

[30] E. Fois, G. Tabacchi, D. Barreca, A. Gasparotto, E. Tondello, Angew. Chem. Int. Ed. 2010, 49, 1944-1948; Angew. Chem. 2010, 122, 1988-1992.

[31] G. Tabacchi, G. Calzaferri, E. Fois, Chem. Commun. 2016, 52 , 11195-11198. R. Arletti, E. Fois, L. Gigli, G. Vezzalini, S. Quartieri, G. Tabacchi, Angew. Chem. Int. Ed. 2017, 56, 2105; Angew. Chem. 2017, 129, 2137

[32] Y. Fang, D. Lesnicki, K. J. Wall, M.-P. Gaigeot, M. Sulpizi, V. Vaida, V. H. Grassian, J. Phys. Chem. A 2019, 123, 983-991.

[33] K. Nakamoto, M. Margoshes, R. E. Rundle, J. Am. Chem. Soc. 1955, 77, 6480-6486.

[34] F. Fontaine-Vive, M. R. Johnson, G. J. Kearley, J. A. K. Howard, S. F. Parker, J. Am. Chem. Soc. 2006, 128, 2963-2969.

[35] M. Gadermann, D. Vollmar, R. Signorell, Phys. Chem. Chem. Phys. 2007, 9, 4535.

[36] M. Wiebcke, G. Engelhardt, J. Felsche, P. B. Kempa, P. Sieger, P. Fischer, J. Phys. Chem. 1992, 96, 392-397.

[37] E. Fois, A. Gamba, J. Phys. Chem. B 1997, 101, 4487-4489.

[38] J. Lu, I. Hung, A. Brinkmann, Z. Gan, X. Kong, G. Wu, Angew. Chem. Int. Ed. 2017, 56, 6166-6170; Angew. Chem. 2017, 129, 6262-6266.

[39] E. A. Carter, G. Ciccotti, J. T. Hynes, R. Kapral, Chem. Phys. Lett. 1989, 156, 472-477.

[40] S. Grimme, J. Comput. Chem. 2006, 27, 1787-1799.

[41] C. Adamo, V. Barone, J. Chem. Phys. 1999, 110, 6158-6170.

[42] W. Caminati, W. Li, L. Evangelisti, Q. Gou, R. Meyer, Angew. Chem. Int. Ed. 2019, 58, 859-865; Angew. Chem. 2019, 131, 869-875.

[43] N. Kungwan, C. Ngaojampa, Y. Ogata, T. Kawatsu, Y. Oba, Y. Kawashima, M. Tachikawa, J. Phys. Chem. A 2017, 121, 7324-7334.

[44] S. D. Ivanov, I. M. Grant, D. Marx, J. Chem. Phys. 2015, 143, 124304.

[45] D. A. Thomas, M. Marianski, E. Mucha, G. Meijer, M. A. Johnson, G. von Helden, Angew. Chem. Int. Ed. 2018, 57, 10615-10619; Angew. Chem. 2018, 130, 10775-10779.

[46] C. Drechsel-Grau, D. Marx, Phys. Chem. Chem. Phys. 2017, 19, 2623-2635.

[47] M. E. Tuckerman, D. Marx, M. Parrinello, Nature 2002, 417, 925-929.

[48] M. Hellström, M. Ceriotti, J. Behler, J. Phys. Chem. B 2018, 122, 10158-10171.

[49] I. Frank, ChemistrySelect 2019, 4, 868-872.

[50] P. Kraus, I. Frank, Chem. Eur. J. 2018, 24, 7188-7199.

[51] C. Qu, J. M. Bowman, Phys. Chem. Chem. Phys. 2019, 21, 3397-3413.

[52] C. Drechsel-Grau, D. Marx, Phys. Rev. Lett. 2014, 112, 1-5.

[53] C. Schran, O. Marsalek, T. E. Markland, Chem. Phys. Lett. 2017, 678, 289-295.

[54] C. Drechsel-Grau, D. Marx, Angew. Chem. Int. Ed. 2014, 53, 10937-10940; Angew. Chem. 2014, 126, 11117-11120.

[55] W. W. Cleland, M. M. Kreevoy, Science 1994, 264, 1887-1890.

[56] A. Langkilde, S. M. Kristensen, L. Lo Leggio, A. Mølgaard, J. H. Jensen, A. R. Houk, J.-C. Navarro Poulsen, S. Kauppinen, S. Larsen, Acta Crystallogr. Sect. D Biol. Crystallogr. 2008, 64, 851-863.

[57] P. Kumar, E. H. Serpersu, M. J. Cuneo, Sci. Adv. 2018, 4, eaas8667.

[58] R. Buzzoni, S. Bordiga, G. Ricchiardi, C. Lamberti, A. Zecchina, Bellussi, Langmuir 1996, 12, 930-940. 


\section{Entry for the Table of Contents}

\section{COMMUNICATION}

By investigating the fate of a Brønsted acid proton we discover the protecting-group ability of $\mathrm{TiO}_{2}$. This new surface chemistry concept has been captured by modeling $\mathrm{HCOOH}$ on top of $\mathrm{TiO}_{2}$ (101) anatase facets. The acid proton is shared between adsorbate and surface forming a Short Strong Hydrogen Bond

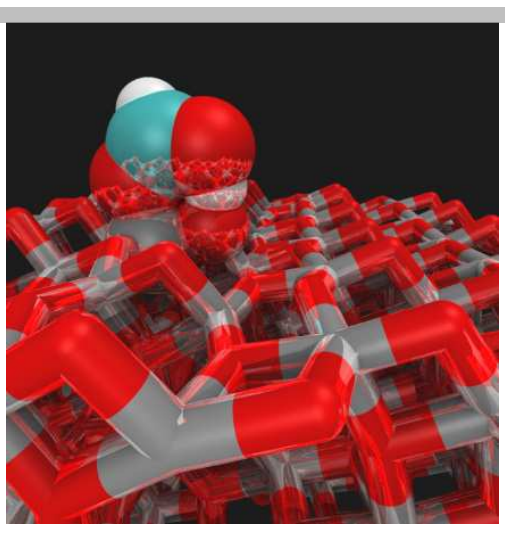

Gloria Tabacchi, Marco Fabbiani, Lorenzo Mino, Gianmario Martra, Ettore Fois*

The case of $\mathrm{HCOOH}$ on (101) anatase $\mathrm{TiO}_{2}$ : where is the acid proton? 